\title{
Globe
}

Revue internationale d'études québécoises

\section{Pierre Nepveu : Intérieurs du Nouveau Monde. Montréal, Boréal, coll. « Papiers collés ", 1999}

\section{Jean-Olivier Vachon}

Volume 2, numéro 1, 1999

URI : https://id.erudit.org/iderudit/1000127ar

DOI : https://doi.org/10.7202/1000127ar

Aller au sommaire du numéro

Éditeur(s)

Globe, Revue internationale d'études québécoises

ISSN

1481-5869 (imprimé)

1923-8231 (numérique)

Découvrir la revue

Citer ce compte rendu

Vachon, J.-O. (1999). Compte rendu de [Pierre Nepveu : Intérieurs du Nouveau Monde. Montréal, Boréal, coll. « Papiers collés », 1999]. Globe, 2(1), 150-151.

https://doi.org/10.7202/1000127ar d'utilisation que vous pouvez consulter en ligne.

https://apropos.erudit.org/fr/usagers/politique-dutilisation/ 


\section{Pierre Nepveu,}

Intérieurs du Nouveau Monde.

Montréal, Boréal, coll. «Papiers collés», 1999.

Amorcée en 1988 avec $L^{\prime}$ Écologie du réel, l'apport de Pierre Nepveu à une redéfinition de la littérature québécoise s'est enrichi il y a quelque temps d'un nouvel essai qui, loin de se concentrer cette fois sur les conséquences d'un pluralisme purement québécois, traverse les frontières en empruntant la notion d' «américanité».

Le projet d'Intérieurs du Nouveau Monde est à première vue ambitieux : proposer une nouvelle lecture de l'expérience américaine qui s'opposerait aux idées de grands espaces, d'aventures surhumaines et de nature inviolée. Mais parce qu'ambitieux, il est animé d'un bout à l'autre d'une passion et d'une sincérité contagieuses, comme si le contact d'une américanité repliée sur elle-même, intime et fragile, donnait à son écriture la confiance tranquille d'un confident. Il n'est pas étonnant d'ailleurs que Nepveu ait entrepris de commencer et de terminer son recueil par le récit personnel d'une rencontre de voyage, ces deux essais autobiographiques, par leurs positions limitrophes, donnant ainsi au recueil le ton approprié à sa lecture, qui est moins celle d'une analyse et d'une démonstration universitaires que celle de rencontres, honnêtes et sensibles, avec des auteurs qui ont vécu l'Amérique de l'«intérieur".

C'est sur un sentiment de privation et de petitesse que s'ouvrent les premiers essais du recueil. Consacrés d'abord à un point de vue strictement féminin (Marie de l'Incarnation, Emily Dickinson, Laure Conan et Hester Prynne), ceux-ci nous entraînent par la suite des poètes américains (Hart Crane, Wallace Stevens, Williams Carlos Williams) aux poètes québécois (Grandbois, Miron, Hébert, Garneau, Lapointe) tout en accordant une place à la poésie autochtone. S'approfondit ici, entre autres, cette idée que l'Ámérique serait par essence réfractaire à toute vie et richesse intellectuelles. $\mathrm{Si}$ "l'Amérique est perdue», pour Williams, c'est qu'elle n'a pas réussi à créer un langage et un esprit en mesure de capter l'immensité du nouveau continent et de créer, par conséquent, une âme 
véritablement américaine. La dernière section du recueil de Nepveu offre peut-être la dimension la plus originale et la plus intéressante. Dans la lignée du projet Montréal imaginaire que Nepveu a dirigé avec Gilles Marcotte pour le 350e anniversaire de Montréal, l'auteur se penche sur un aspect fondamental de notre habitation du continent : la ville. Érigées au hasard des vagues de colonisation, souvent anonymes et sans personnalité, ces villes nord-américaines reflètent fort bien ce qu'a pu être l'âme d'un individu devant cette immensité du Nouveau Monde : fragilité, tâtonnements, effacement. Comme si l'ouverture de trop grandes possibilités débouchait irrémédiablement sur un sentiment de vide ou de trop-plein et sur l'impossibilité angoissante d'envahir efficacement l'espace.

François Dumont, dans un étude consacrée aux recueils d'essais de la collection «Papiers collés», aux Éditions du Boréal (dans laquelle est publié l'ouvrage de Nepveu), démontrait qu'une caractéristique commune de ces recueils, outre l'utilisation récurrente du paradoxe, était leur caractère einachevé, 1 . Paradoxaux, assurément les textes d'Intérieurs du Nouveau Monde le sont : ne serait-ce que par la confrontation d'une subjectivité fragile à la majesté naturelle d'un continent. Mais dans ce cas-ci, c'est plutôt leur caractère inachevé qui domine, non pas cependant par un manque de rigueur ou l'absence d'éléments essentiels - au contraire -, mais plutôt par le projet embrassé au départ par Nepveu : suggérer, par une lecture nonexhaustive, une facette jusque là mal connue du "Nouveau Monde». Car il s'agissait moins ici de reformuler définitivement cette idée d'américanité que de nous en faire découvrir la version plus intime, intérieure, et, on le voit, tout aussi pertinente.

Jean-Olivier Vachon Université McGill

1 François Dumont, «L'essai littéraire québécois des années quatre-vingt : la collection

"Papiers collés" $¥$, Recherches sociographiques, vol. XXXIII, no 2, 1992, p. 323. 